\title{
SOCIOECONOMIC CORRELATES OF PERCEPTIONS OF SUSTAINABILITY OF PASTORAL LIVELIHOOD AMONG CATTLE HERDSMEN IN KWARA STATE, NIGERIA.
}

\author{
ADISA R. S. ${ }^{1}$ and BADMOS A. H. A. ${ }^{2}$ \\ ${ }^{1}$ Department of Agricultural Extension and Rural Development, \\ University of Ilorin, PMB 1515, Ilorin, Nigeria \\ ${ }^{2}$ Department of Animal Production, University of Ilorin, PMB 1515, Ilorin, Nigeria \\ Corresponding Email: rsadisa@yahoo.com
}

\begin{abstract}
The paper provides empirical evidence on the perception of sustainability of pastoral livelihood among its practitioners in Kwara State, Nigeria. Multi-stage cluster random sampling was used in sample selection, while an interviewer-administered questionnaire was used to elicit information. A Pastoral Livelihood Sustainability Perception Index (PLSPI) was computed for each respondent, using 10 positively presented perception statements on a 5-point Likert type scale. Data analysis revealed that respondents were mostly male, uneducated, and fairly young. Mean monthly income and herd size were N203, 393 and 41 respectively. Respondents exhibited highly favourable perception of pastoral livelihood sustainability $(=4.2)$. Also, there were significant correlations between PLSPI and age $(r=0.65)$, income $(r=0.72)$, herd size $(r$ $=0.78)$, and years of education $(r=-0.68)$. Pastoralism is not just a function of culture but also that of rational income generation. Intensification of formal education among pastoralist youth and children is thus recommended as a means of personal and future development of pastoral households.
\end{abstract}

Key words: Pastoralism, Perception, Sustainability, Income, Herd Size,

\section{INTRODUCTION}

The vital role of agriculture in the development of the economies of Third World countries is undeniable (Eastwood, Kirsten, and Lipton, 2007). Nigeria, with a population of about 140 million people, occupying a land area of 923,773 square kilometers, continues to benefit immensely from agricultural production activities. With about 82 million hectares of arable land, of which only 42 percent is so far cultivated, agriculture contributed between 31.2 percent and 39.2 percent of total GDP between 1986 and 1995, and over 40 percent between 1999 and 2006 (Nigeria Economic Intelligence Unit, 2007). Livestock production accounted for about 20 percent of these figures. Thus, the importance of livestock production cannot be overlooked, as it 
converts biomass that is not directly useful to man into animal products that serve strategically useful purposes for human existence (Ingeval, Hollands and Roem, 2005).

Livestock production, particularly ruminants, is concentrated in the savannahs and semi-arid zones mainly by pastoralist Fulani who control about $90 \%$ of the nation's livestock population (Iro, 1994). Using mobility as a production stratagem, the Fulani herdsman is constantly in search of pasture, water, market and crop residues for his herd. While doing this, he must avoid tsetse fly, inclement weather, tribal enemies, livestock bandits and hostile social environment (Iro, 1994). Still, he struggles with competing land users, chiefly arable crop farmers who are equally of strategic importance to the nation.

The optimum Fulani cattle herd size lies between 80 and 100, although Cunnings (1966) found 100-150. Iro (1994), from whose study much of the details on the Fulani herding system herein described were derived, gave a vivid documentation of the herding system of the Fulani in Nigeria. With a preponderance of female over male at ratio 4:1, the Fulani maintains a balanced functional species composition that is made up of beefers, milkers, breeders, carriers, and stock beautifiers. Iro (1994) also stated that the slowmaturing Sokoto Red cow and the lyre-horned White Fulani cattle are the mainstay of the pastoral Fulani holdings. White and Wickens (1976) disclosed that the White Fulani, though less hardy, has higher milk and beef yield compared with the Sokoto Red.

Cattle belonging to individual family members are usually herded together, with male family members assuming automatic rights to all cattle, making it difficult to determine cattle ownership by female family members. Fulani men possessing less than twenty cows are seen as poor, while women having six cows are considered as rich (Iro, 1994). Women, however, own most of the small ruminants and all of the poultry (Swinton, 1987). Though most Fulani men herd cattle well pass the middle age, herding is dominated by the youths, while decisions about grazing are mainly made by the elderly family members. The Fulani herdsman makes excellent use of sign language, the cane and verbal command to drive the animals, with faster animals occupying the front rows. During migration, a typical herd consisting of several family units move in a column of up to five meters wide and two kilometers long. And by the time it passes any given point, 'everything that stands at that point is destroyed' (Fricke, 1979; and Vengroff, 1980).

Describing the annual herding cycle of the Fulani, Iro (1994) stated further that the herding season begins with southward movement of the herd and along rivers and stream valleys from October to December marking the end of rainy season and beginning of dry season. January to February is the harmattan season that is characterized by longer grazing hours, herd splitting, and more frequent visits to stable water sources. These thus increase southward movement of the herds. The months of March and April are usually the toughest for the herdsman and his cattle, as it is the hottest period in the grazing calendar. In deed, he now herds his cattle only in the evenings and nights (Riesman, 1977). May and June signify the end of dry season and vegetation begins to appear. This also marks the beginning of northward movement of cattle herds. From this period up till 
September, which is the peak of rainy season, though characterized by cattle-breeding, more milk production and shorter grazing hours, cattle herding coincides significantly with arable crop production.

According to Iro (1994), herding is a daunting task, and contrary to widespread belief, it is not the delight of the Fulani- they herd not as a matter of choice but as a necessity. Iro (1994) found that about $75 \%$ of the sampled nomadic pastoralists maintained that cattle herding is not only toilsome, but also becoming increasingly strenuous. Scones (2008) reported high cattle-pastoralist ratios and concluded that there was need to reduce herder population through diversification of instrument. This was carried out on 10 respondents that would not be included in the sample. The value of coefficient of correlation " $r$ " was found to be .89 , which implied that the instrument was reliable.

A Pastoral Livelihood Sustainability Perception Index (PLSPI) was calculated for each respondent based on responses from 10 positively presented sustainability perception statements on a 5-point Likert-type scale. The five points on the scale were weighted on the basis of level of agreement with the respective statements: (strongly agree, $S A=5$ ), (agree, $\mathrm{A}=4$ ), (undecided, $\mathrm{UD}=3$ ), (disagree, $\mathrm{D}=2$ ), (strongly occupations. However, according to Davies and Bennet (2007), alternative occupations among herdsmen are limited and that switching to agriculture was considered as not being economically worthwhile by pastoralists. Also, certain encumbrances such as resource-based conflicts with other user-groups (particularly farmers), increasing scarcity of herbage for feeding of cattle, and negative demographic consequences associated with contemporary pastoral livelihood have seemingly lent some credence to deep pessimism concerning the future of pastoralism expressed by a growing number of scholars including Sanford (2008) and Adisa (2009).

It is therefore imperative to conduct studies that focus on reconciling present realities with the need for cattle breeding in Nigeria. A starting point, perhaps, is gauging of the opinions of stakeholders. The present study, therefore, attempts to analyze the perceptions of pastoralists on the sustainability of their chosen occupation against the backdrop of seemingly unfavorable contemporary realities and criticisms. The specific objectives of the research are to:

(a) describe the personal and occupational characteristics of pastoralists in the study area;

(b) analyze pastoralist's perceptions on sustainability of pastoral livelihood; and

(c) determine the socio-economic correlates of respondents perceptions of sustainability of pastoral livelihood. 


\section{METHODOLOGY}

Lying in the middle belt of Nigeria, Kwara State has a land area of $32,500 \mathrm{~km} \mathrm{sq}$ made of Guinea Savannah vegetation to the south and Derived Savannah to the North. There is also a Fadama belt that stretches the length of the River Niger. Annual rainfall is between $1000-1500 \mathrm{~mm}$ while maximum average temperatures are between $30^{\circ}$ and $35^{\circ}$ Celsius (Kwara State Diary, 2007). Agriculturally, the State is significant for food production in Nigeria because of its rich soil that supports the cultivation of many crops. The state has a cultivable land area of 2,447, 250ha (Kwara State Planning Commission, 2004). Similarly, it has abundant livestock that comprises of cattle, goats and sheep. It shares an international boundary with the Republic of Benin, and has four main ethnic groups namely, Yoruba, Nupe, Baruba and Fulani.

Four-stage cluster random sampling procedure was used to select respondents for the research. Out of the 16 LGAs in the state, six were randomly selected-namely: Asa, Edu, Ifelodun, Ilorin East, Kaiama, and Moro LGAs. In each LGA, 10 cattle herdsmen were randomly selected for data collection. This was done by randomly selecting two herdsmen from five transit camps in each LGA. This gives a total of 60 herdsmen. The Test-retest method was used to determine the reliability of the disagree, $\mathrm{SD}=1$ ). The maximum possible score was thus 50 (i.e. $5 \times 10$ ), while the minimum possible score was 10 (i.e. 1x10). The PLSPI for each respondent was derived by expressing the score as a percentage.

\section{Socioeconomic Characteristics of Respondents}

RESULTS AND DISCUSSION

Table 1 summarizes the findings concerning some personal and occupational and occupational characteristics of respondents. The mean age was 29 years while the 
Table 1: Personal and Occupational characteristics of Respondents $(\mathrm{N}=56)$

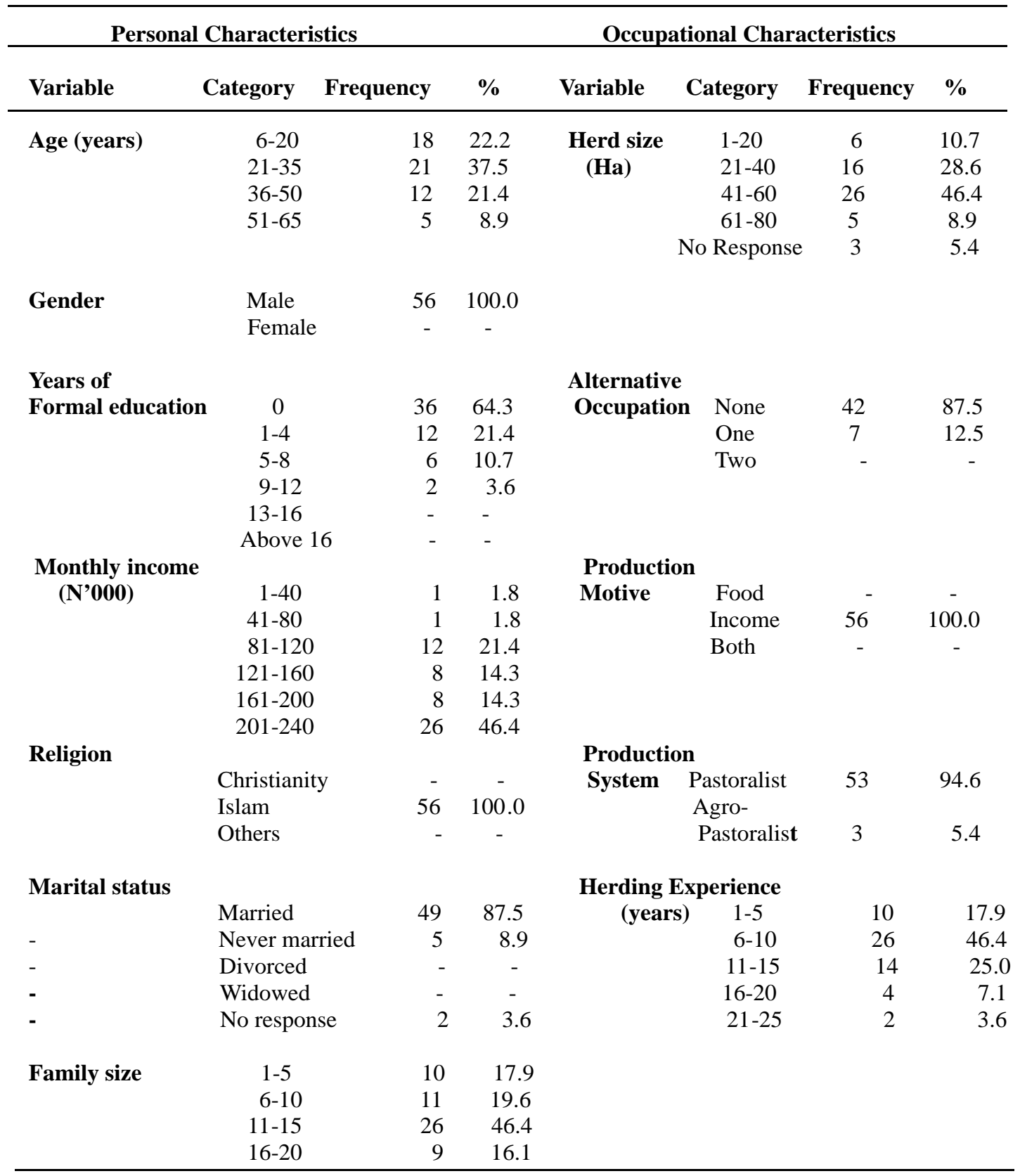

Note: Mean age $=29.0$ years; Mean income $=$ N203, 393; while the mean family size was 9; Mean herd size $=41$ and Mean herding experience $=9.1$ years $\quad$ (Source: Field Survey, 2008). 
modal age range was 21-35 years, accounting for $37.5 \%$. These indicate, perhaps, that cattle herding attracts more youths than older people. This may be due to the possibility that youths are more able to withstand the rigours of transhumance associated with cattle herding. That cattle herding is entirely male dominated was evident from the findings in Table 1. Consistent with the results of research by Gurung (2006), all respondent herdsmen were male. Only about $14 \%$ of herdsmen benefited from formal education. Indeed, about $64 \%$ of herdsmen interviewed had no education at all. This pathetically low level of education among pastoralists is buttressed by the study of Aikman (2008) which revealed very low school enrollment rates and high drop-out rates among school-age pastoralists. Table 1 further reveals relatively high income generation among respondents. About $96 \%$ of respondents earned more than N80, 000 (USD500) monthly, while mean monthly income for the sample was N203, 393 (USD1271. 20). Indeed, about $46 \%$ actually earned more than N200, 000 (USD1250) per month. This implies that the vast majority of respondents were leaving well above poverty line. Average cattle herd size was 41 , while majority of herdsmen (46.4\%) herded 41-60 cattle. All respondents claimed that income-earning was their primary motive of production, even though about $13 \%$ were involved in one other type of occupation including arable crop farming. Nearly $80 \%$ of respondents had herded cattle for at least 5 years.

\section{Perception of Pastoral Livelihood among Respondents}

Table 2 shows the summary of results of the investigation of perception of pastoral livelihood among the respondents. Convincingly, Table 2 reveals that respondents generally exhibited favourable perception towards pastoral livelihood, as shown by the fact that the level of agreement with the perception variables was approximately 4.0.

Table 2 Perception of Sustainability of Pastoral Livelihood among Respondents

\begin{tabular}{lc}
\hline Perception & Mean Score \\
\hline 1. Cattle herding is still rewarding & 4.15 \\
2. Cattle herding is more profitable than before & 3.80 \\
3. Youths of pastoral households are interested in cattle herding & 3.05 \\
4. My children should embrace pastoral livelihood & 3.75 \\
5. Pastoralists should not be encouraged to settle down & 4.10 \\
6. The future of Pastoralism in Nigeria is bright & 4.25 \\
7. Pastoralists need not have alternative occupation(s) & 4.15 \\
8. Pastoralism does more good than harm to the environment & 4.05 \\
9. Pastoralists are not to blame for resource-based conflicts with other users & 4.05 \\
10. Pastoralists have high job satisfaction & 4.20 \\
\hline Grand Mean Score & 39.55 \\
Level of agreement with perception variables & 3.96 \\
\hline
\end{tabular}


Table 2 shows that respondents perceived cattle herding as a rewarding vocation $(\mathrm{MS}=4.15)$ and that cattle herding was more profitable than before $(\mathrm{MS}=3.80)$. This might not be unconnected with the high unit price of cattle. An informal survey of cattle markets in the study area revealed that a medium-sized bull sold for between N46, 000 and N60, 000. However, while respondents mostly agreed that their children should embrace cattle herding as future occupation $(\mathrm{MS}=3.75)$ and despite the perceived prosperity associated with cattle herding, they exhibited uncertainties over youths' current enthusiasm towards pastoral livelihood $(\mathrm{MS}=3.05)$. This perhaps indicates that youths of pastoral households might be experiencing waning interests in cattle herding as a vocation. Table 2 however further revealed that respondents held very favourable perceptions on the remaining statements used in measuring perception of pastoral livelihood sustainability among respondents. For instance, they generally agreed that pastoralism in Nigeria has a bright future ( $M S=4.25)$, and that there was no need for the sedenterization of pastoralists $(\mathrm{MS}=4.10)$. This probably implies that the present generation of pastoralists not only believed in the survival of their occupation, but might be vehemently opposed to any attempt to make them abolish their current production practices. Also, respondents believed they were satisfied with their job (MS=4.20), and this perhaps informed their seeming lack of interest in job diversification (MS=4.10). Furthermore, Table 2 also revealed that respondents generally perceived that their production activities do not, ultimately, impact negatively on the environment. Indeed, they opined that their production system din more good than harm to the environment $(\mathrm{MS}=4.05)$. With a mean score of 4.05 , respondents also did not believe that they were to be blamed for the increasing rate of conflicts between them and other user-groups of common production resources, particularly arable crop farmers (Table 2). This is in spite of the fact that cattle herdsmen also conceded that conflict with herdsmen was their 'most important' production problem (van't Hooft, Millar and Django, 2005).

\section{Correlates of Perception of Sustainability of Pastoral Livelihood}

An important objective of this research was to determine the socioeconomic variables that were associated with the perception of sustainability of pastoral livelihood among respondents. Table 3 summarizes the findings in this regard. It was found that, at $.05 \mathrm{a}$ priori level of significance, years of education (-.68), monthly income (.72), herding experience (.64), and herd size (.78). Age and size of household did not significantly correlate with PLSPI among respondents. 
Table 3: Results of Pearson correlations of Pastoral Livelihood Sustainability Perception Index (PLSPI) with Socioeconomic variables among Respondents

\begin{tabular}{lcl}
\hline Variables & Correlation coefficient & p-value \\
\hline Age & .65 & .106 \\
Years of education & -.68 & $.002^{*}$ \\
Family size & .23 & .198 \\
Herding experience & .64 & $.017^{*}$ \\
Income & .72 & $.005^{*}$ \\
Herd size & .78 & $.013^{*}$ \\
\hline
\end{tabular}

*Significant at $5 \%$

Years of formal education inversely but significantly correlated with PLSPI among respondents, implying that favourable perception of sustainability of pastoral livelihood decreased with increasing level of formal education. This, perhaps, indicate education could be a tool to achieve occupational re-orientation among pastoral households. PLSPI, however, increased with increasing years of herding experience among respondents. This means that the more the number of years respondents spent as cattle herdsmen, the more favourable their perception of sustainability of pastoral livelihood. This might be due to the fact their experience as cattle herdsmen had been economically beneficial. Income and herd size also positively and significantly correlated with perception of pastoral livelihood sustainability among respondents. This indicates that increasing favourable perception of sustainability of cattle herding might be significantly determined by herd size and, consequently, income earnings and that profitability and economic prosperity might also be major attractions to pastoralists apart from cultural compatibility.

\section{CONCLUSION AND POLICY IMPLICATION OF FINDINGS}

The study essentially focused on how cattle herdsmen perceived the present and future existence of their vocation. The demographic features of respondents still portrayed pastoral livelihood as being essentially dominated male who were mostly youths with very little or no formal education, despite educational interventionist programmes of governments and NGOs. And contrary to the conservative lifestyles and living conditions of pastoralists, the study reveals that pastoralism was, at least by Nigerian standards, a prosperous vocation. This relative prosperity associated with cattle herding could, perhaps among other things, be responsible for the pervasive favourable perception of its sustainability among respondents. Other socioeconomic variables associated with the observed favourable perception among respondents were herding experience and years of formal education. While favourable perception increased with 
the former, it decreased with an increase in the latter. It is thus evident that formal education is crucial in shaping the perceptions of pastoralism among its practitioners.

Based on the findings of this study, it is hereby recommended that, since cattle herdsmen are still passionate about their production system for economic reasons, any form of reorientation of cattle herdsmen should be preceded by programmes that would encourage them to diversify their income-generating activities. This could be done through planned entrepreneurial and technical skill acquisition programmes. They could also be encouraged to invest their resources in agro-allied and other cottage industries. It is also imperative that children and youths of pastoral households be deliberately motivated to further their education in institutions of higher learning. Limiting educational interventionist efforts to primary/secondary levels does not portend good omen for the much desired positive changes in pastoral households.

\section{REFERENCES}

Adisa, R. S. (2009). 'Correlates of Conflicts between Arable Crop Framers and Cattle Herdsmen in Kwara State, Nigeria'. Unpublished Ph. D. Thesis, Department of Agricultural Extension and Rural Development, University of Ilorin, Ilorin, Nigeria.

Cunnings, I. (1966). Baggara Arabs. London: Oxford University Press. : 31

Davies, J. and Bennett, R. (2007). Livelihood Adaptation to Risk: Constraints and Opportunities for Pastoral Development in Ethiopia's Afar Region. Journal of Development Studies, 43 (3): 490-511

Eastwood, R; Kirsten, J; and Lipton, M. (2006). Premature Deagricuturalization? Land Inequality and Rural Dependency in Limpopo Province, South Africa. Journal of Development Studies, (42) 8 : 1325-1349.

Fricke, W. (1979). Cattle Husbandry in Nigeria: A Study of its Ecological Conditions and Social-Geographical Differentiations. Translated by J. Hellen and G. Cockburn. Heidelberg. : 13-20

Ingeval, A; J. Hollands and W. Roem (2005) "The Contribution of Small Animals". LEISA. 21(3): 13 - 15 Amersfoort, Netherlands

Iro, I. (1994). The Fulani Herding System, Washington, African Development Foundation. :6-12.

Kwara State Government (2007). Kwara State Diary, 2007. : :12-22 
National Economic Intelligence Unit (2007). Annual Statistics, Abuja Nigeria.

Riesman, P. (1977). Freedom in Fulani Social Life: An Introspective Ethnology. Translated by M. Fuller. Chicago: The University of Chicago Press. : 23

Scoones, I. (2008). 'Too many people, too few livestock: pastoralism in crisis?' Available at http://www.future- agriultures.org/pastoralism_debate.html. Retrieved 17th May, 2009.

Swinton, S. (1987). Drought Survival Tactics of Subsistence Farmers in Niger. Human Ecology, 1(2): 108 - 122.

Vengroff, R. (1980). Upper Volta: Environmental Uncertainty and Livestock Production. Texas. : 13

White, L. and Wickens, G. (1976). Land-use in the Southern Margins of the Sahara In Management of Semi-arid Ecosystem. Edited by B. Walker. Amsterdam:Elsevier Scientific Publishing Company. : 26 